\title{
Inaccurate Group Meta-Perceptions Drive Negative Out-Group Attributions in Competitive Contexts
}

\section{Citation}

Lees, Jeffrey, and Mina Cikara. "Inaccurate Group Meta-perceptions Drive Negative Out-group Attributions in Competitive Contexts." Nature Human Behaviour 4, no. 3 (2019): 279-86

\section{Permanent link}

http://nrs.harvard.edu/urn-3:HUL.InstRepos:42658677

\section{Terms of Use}

This article was downloaded from Harvard University's DASH repository, and is made available under the terms and conditions applicable to Other Posted Material, as set forth at http:// nrs.harvard.edu/urn-3:HUL.InstRepos:dash.current.terms-of-use\#LAA

\section{Share Your Story}

The Harvard community has made this article openly available.

Please share how this access benefits you. Submit a story.

\section{Accessibility}




\section{Inaccurate group meta-perceptions drive}

\section{negative out-group attributions in competitive}

\section{contexts}

Jeffrey Lees ${ }^{1 *}$, Mina Cikara ${ }^{2} *$

${ }^{1}$ Harvard Business School, Harvard University, Boston, MA USA

${ }^{2}$ Psychology Department, Harvard University, Cambridge, MA USA

* Corresponding Authors: Jeffrey Lees (jlees@g.harvard.edu); Mina Cikara (mcikara@fas.harvard.edu) 


\begin{abstract}
Across seven experiments and one survey $(\mathrm{N}=4282)$ people consistently overestimated out-group negativity towards the collective behavior of their in-group. This negativity bias in group metaperceptions (GMPs) was present across multiple competitive (but not cooperative) intergroup contexts, and appears to be yoked to group psychology more generally; we observed negativity bias for estimation of out-group, anonymized-group, and even fellow in-group members' perceptions. Importantly, in the context of American politics greater inaccuracy was associated with increased belief that the out-group is motivated by purposeful obstructionism. However, an intervention that informed participants of the inaccuracy of their beliefs significantly reduced negative out-group attributions, and was more effective for those whose GMPs were more inaccurate. In sum, we highlight a pernicious bias in social judgments of how we believe 'they' see 'our' behavior, demonstrate how such inaccurate beliefs can exacerbate intergroup conflict, and provide an avenue for reducing the negative effects of inaccuracy.
\end{abstract}




\section{Main}

How we believe others perceive us - meta-perception — plays a critical role in how we interact with others ${ }^{1-3}$. In the context of intergroup interactions, these meta-perceptions may bring unpleasant, even harmful evaluations to $\operatorname{mind}^{4-8}$. For example, when individuals believe they are being negatively stereotyped by an out-group member, they experience increased negative emotions and lower self-esteem ${ }^{4}$, suffer increased anxiety ${ }^{9}$, and subsequently exhibit more intergroup bias ${ }^{10}$.

Despite the important role that beliefs about how 'they' see 'us' (and our actions) play in intergroup relations ${ }^{11-14}$, past work has focused primarily on person-to-person interactions across group boundaries or on estimates of extremity of and polarization in out-group attitudes ${ }^{15-18}$. As an example of the latter, findings in the domain of values and attitudes indicate that group members overestimate the level of disagreement and polarization between groups (though note that these constitute first order judgments, or "how I see X") ${ }^{16-18}$. Evidence from the intergroup literature, more broadly, suggests that group labels exacerbate inaccuracy in social judgments because they activate stereotypes that cause people to adjust their judgments away from their initial, more accurate anchors ${ }^{12}$.

There is, in complement, a growing literature in the domain of second-order, intergroup meta-judgments (or "what I think they think about us"), which reveals that people tend to have overly negative and inaccurate judgments of out-group motives toward the in-group ${ }^{11,14}$. This foundational work on the effects of meta-perceptions in intergroup contexts raises two important questions: (i) are these meta-perceptions accurate?; and (ii) what happens when these judgments are made in response to collective action — when people consider how 'they' see 'our' (not my) behavior? 
Here, we tackle a particular form of intergroup (in)accuracy by examining group metaperceptions (GMPs): how we believe our group's collective actions will be perceived by the outgroup. In our view, GMPs represent an intergroup-context activated distortion of second-order judgments. This makes GMPs (i) distinct from first-order judgments and (ii) unique in that they should be sensitive to functional relations between groups (i.e., whether groups are cooperative, competitive) but relatively invariant to the focal event/act/behavior or the groups in question.

GMPs likely serve an important role in determining the course of group-on-group interaction because they allow us to make predictions about whether an out-group will be supportive or hostile towards our own group's efforts at cooperation; therefore, GMPs should also drive emotions, strategy, and policy preferences. For example, U.S. President George W. Bush, in his address to a joint session of Congress on September $20^{\text {th }}, 2001$ laid out in stark terms how he believed Al-Qaeda perceived the United States, and how these second-order judgments ought to compel US foreign policy ${ }^{19}$ : “Americans are asking 'Why do they hate us?' They hate what they see right here in this chamber: a democratically elected government...They hate our freedoms: our freedom of religion, our freedom of speech, our freedom to vote and assemble and disagree with each other...We will direct every resource at our command - every means of diplomacy, every tool of intelligence, every instrument of law enforcement, every financial influence, and every necessary weapon of war- to the destruction and to the defeat of the global terror network....Every nation in every region now has a decision to make: Either you are with us or you are with the terrorists." President Bush used the belief that "they hate our freedoms" to motivate his call to war and his ultimatum to other countries that they are either "with us" or "with the terrorists." However, many have noted that this belief that Al-Qaeda "hate our freedoms" wrongly diagnosed the motivations of Al-Qaeda and the complex socio-political 
forces which drove their perception of the United States ${ }^{20,21}$. Furthermore, this essentializing language served to dehumanize Muslims and drive support for the "War on Terror" among the American public ${ }^{22}$.

This example highlights how inaccurate, and overly negative, beliefs about how the outgroup perceives the behavior (and values) of one's own group can drive intractable intergroup conflict. When group leaders and other group members believe the out-group will react with animosity and perceive one's group in a highly negative fashion, they are likely to support antagonistic intergroup actions over cooperative and reconciliatory behaviors. For example, when people believe they are dehumanized by an out-group, they are more likely to dehumanize the out-group in return, which leads to increased support for war and out-group torture ${ }^{7}$. This dynamic can unfold in contexts as hostile as war between nations, but also legislative compromise across political parties, competitive sports, and interaction between organizations. Nonetheless, interventions which directly inform individuals of their inaccurate beliefs may be able to induce positive behavioral change $\mathrm{e}^{23,24}$.

To investigate the nature of GMPs we constructed a set of scenarios involving grouplevel conflict. For Experiments 1, 3, 4, 6 and Study 5 these scenarios pertained to the behavior of American political parties in a legislative context. In Experiment 2 the scenarios pertained to group-level conflict between men and women in educational and workplace settings. All scenarios presented instances where one group was attempting to pass a law or change a policy in a manner which would potentially disadvantage the other group (e.g., requiring a sitting governor of the opposing party to disclose their taxes), except for Experiment 3 where the behavior would potentially benefit the other group. Supplemental Experiment A is a direct 
replication of Experiment 4 with a convenience sample, and Supplemental Experiment B is an exploratory follow up to Experiment 6.

Experiments 1-4 were designed to test for participant accuracy in GMPs. At the beginning of these experiments participants were asked to identify their political affiliation (or gender identity in Experiment 2) and were then randomly assigned to whether the group taking action in the scenario was their in-group or out-group. Those who read about their in-group taking action were asked for their GMPs (e.g. "How much do you believe an [out-group member] will dislike this action?"), whereas those who read about their out-group taking action against their in-group were asked for their actual perceptions (e.g. "How much do you dislike this action?"). In Experiment 4 we also asked about "in-group perceptions" (e.g., "How much do you believe an [in-group] members will dislike the [out-group] action?”). This manipulation allowed for a direct test of participant accuracy vs. perception across both groups (i.e., Democrats vs. Republicans; men vs. women).

When reading the scenarios participants were asked, either as a meta, actual, or in-group perception, their perceived dislike of, opposition to, and political/social unacceptability of the action being taken in the scenario, which they reported on sliding scales, with labels at the end of the scales (e.g., 1="Not Opposed", 100="Extremely Opposed"). After the ratings all participants, across all experiments and Study 5, completed a comprehension check which asked them to identify the group "taking action" in the scenario. Any participants who failed this check were excluded from all analyses. Lastly, all participants were asked their age, gender, and whether they had comments for the experimenters (except in Experiment 4 in which demographic questions were asked at the beginning of the experiment). 
All materials, data, and analysis code for all experiments and studies, and preregistrations for Experiments 4 and 6, are available on OSF: https://osf.io/zhysa/

\section{Results}

Experiments 1-4 and Study 5 were analyzed using mixed-effect beta-regressions and Experiment 6 was analyzed using linear mixed-effects regression. All tests are two-sided. In Experiment 6 homoscedasticity and normality of errors was assumed but this was not formally tested. Further details regarding the analyses can be found in the Methods section.

In Experiment $1(\mathrm{~N}=408)$, participants were randomly assigned to the GMP condition $(\mathrm{N}=129$,$) , actual-perception condition (\mathrm{N}=143)$, or an unlabeled and anonymized control metaperception condition $(\mathrm{N}=136)$ where participants were asked how "Party B" would perceive the behavior of "Party A." Within each condition, participants were randomly assigned to read one of five scenarios (we included multiple scenarios in each experiment and study to assess the robustness of our effects and modeled scenario as a random effect).

Across all scenarios, participants in the GMP condition significantly overestimated the negative perceptions of out-group participants (i.e., participants in the actual-perception condition) on our three measures: action dislike $(b=1.51,95 \% \mathrm{CI}=[1.19,1.83], \mathrm{OR}=4.53, \mathrm{z}=9.27$, $P<0.001)$, opposition to the action $(b=1.40,95 \% \mathrm{CI}=[1.09,1.72], \mathrm{OR}=4.08, \mathrm{z}=8.78, P<0.001)$, and political unacceptability of the action $(b=1.36,95 \% \mathrm{CI}=[1.04,1.67], \mathrm{OR}=3.89, \mathrm{z}=8.46, P<$ 0.001). Similarly, participants in the control meta-perception condition significantly overestimated the negative perceptions of those in the actual-perception condition: dislike $(b=1.32,95 \% \mathrm{CI}=[1.02,1.62], \mathrm{OR}=3.74, \mathrm{z}=8.55, P<0.001)$, opposition $(b=1.22,95 \%$ $\mathrm{CI}=[0.93,1.52], \mathrm{OR}=3.40, \mathrm{z}=8.15, P<0.001)$, and political unacceptability $(b=1.13,95 \%$ $\mathrm{CI}=[0.83,1.42], \mathrm{OR}=3.08, \mathrm{z}=7.45, P<0.001)$. Pairwise post-hoc tests indicate no statistically 
significant difference between responses in the control meta-perceptions condition vs. the GMP conditions: dislike $(b=-0.19,95 \% \mathrm{CI}=[-0.54,0.15], \mathrm{OR}=0.83 t(402)=-1.30, P=0.40)$, opposition $(b=-0.18,95 \% \mathrm{CI}=[-0.52,0.16], \mathrm{OR}=0.83, t(402)=-1.24, P=0.43)$, and political unacceptability $(b=-0.23,95 \% \mathrm{CI}=[-0.58,0.11], \mathrm{OR}=0.79, t(401)=-1.58, P=0.26)$. We also examined the main effect of accuracy by party, modeled as a categorical fixed effect with two groups: "Democrat Accuracy"-Democrats in the GMP and control conditions compared with Republicans in the actual-perception condition — and "Republican Accuracy"-Republicans in the GMP and control conditions compared with Democrats in the actual-perception condition (see Methods for model details). This approach allowed the main-effect to appropriately contrast meta/control vs. actual perceptions (the baseline in the analyses) across parties, rather than within party. Indeed, there was no statistically significant main effect of party accuracy: dislike $(b=-0.04,95 \% \mathrm{CI}=[-$ $0.29,0.21], \mathrm{OR}=0.96, \mathrm{z}=-0.32, P=0.75)$, opposition $(b=-0.00,95 \% \mathrm{CI}=[-0.25,0.24], \mathrm{OR}=1.00$, $\mathrm{z}=-0.03, P=0.98)$, and political unacceptability $(b=-0.02,95 \% \mathrm{CI}=[-0.27,0.23], \mathrm{OR}=0.98, \mathrm{z}=-$ $0.18, P=0.85)$. Finally, pairwise post-hoc tests found no statistically significant differences when examining whether Democrats and Republicans differed in their actual perceptions of the scenarios: dislike $(b=0.00,95 \% \mathrm{CI}=[-0.61,0.61], \mathrm{OR}=1.00, t(400)=0.02, P=1.00)$, opposition $(b=0.15,95 \% \mathrm{CI}=[-0.45,0.74], \mathrm{OR}=1.16, t(400)=0.72, P=0.98)$, and political unacceptability $(b=0.11,95 \% \mathrm{CI}=[-0.49,0.71], \mathrm{OR}=1.11, t(399)=0.51, P=1.00)$. See Figure 1 for a visualization of the raw data by condition.

As predicted, GMPs in Experiment 1 were significantly more negative than participants' actual perceptions of the out-group's behavior. This was true even when we removed party labels. Thus, merely invoking the political intergroup context was enough to engender inaccuracy, supporting our proposition that GMPs are an intergroup-context activated distortion, 
invariant to the groups in question. Furthermore, we found no credible evidence that this effect was moderated by participants' party membership. This suggests that Democrats and Republicans were equally pessimistic, and therefore inaccurate, in judging how members of the other party perceived the collective behavior of their own party.

To further examine the generalizability of our findings, Experiment $2(\mathrm{~N}=286)$ utilized a design similar to that of Experiment 1, but in the context of gender relations. There were two changes from the design of Experiment 1. First, participants were assigned to one of three scenarios regarding group-level gender conflict (e.g., integrating a single-gender school choir), rather than five scenarios regarding political conflict. Second, we did not include an anonymized-group control condition. As with Experiment 1, participants were randomly assigned to the GMP condition $(\mathrm{N}=128)$ or actual perception condition $(\mathrm{N}=158)$, read only one scenario, and responded to items regarding perceived dislike of, opposition to, and social unacceptability of the action in the scenario.

Results indicated a significant condition (actual vs. meta perception) by gender-accuracy interaction (i.e., a fixed effect similar to "party accuracy" in Experiment 1, contracting accuracy across gender rather than within gender), indicating that one gender had more inaccurate GMPs than the other: dislike $(b=0.78,95 \% \mathrm{CI}=[0.22,1.34], \mathrm{OR}=2.18, \mathrm{z}=2.73, P=0.006)$, opposition $(b=0.74,95 \% \mathrm{CI}=[0.18,1.30], \mathrm{OR}=2.09, \mathrm{z}=2.59, P=0.010)$, and social unacceptability $(b=0.65$, $95 \% \mathrm{CI}=[0.09,1.21], \mathrm{OR}=1.92, \mathrm{z}=2.27, P=0.023)$. Pairwise post-hoc tests revealed that female participants had highly negative and inaccurate GMPs, replicating Experiment 1: dislike ( $b=-$ $1.13,95 \% \mathrm{CI}=[-1.66,-0.59], \mathrm{OR}=0.32, t(280)=-5.42, P<0.001)$, opposition $(b=-1.07,95 \% \mathrm{CI}=[-$ $1.60,-0.54], \mathrm{OR}=0.34, t(280)=-5.22, P<0.001)$, and social unacceptability $(b=-1.02,95 \% \mathrm{CI}=[-$ $1.56,-0.49], \mathrm{OR}=0.36, t(280)=-4.93, P<0.001)$. However, male participants' GMPs were not 
significantly different from the actual perceptions of female participants: dislike $(b=-0.35,95 \%$ $\mathrm{CI}=[-0.86,0.17], \mathrm{OR}=0.71, t(280)=-1.74, P=0.30)$, opposition $(b=-0.33,95 \% \mathrm{CI}=[-0.85,0.20]$, $\mathrm{OR}=0.72, t(280)=-1.69, P=0.33)$, and social unacceptability $(b=-0.37,95 \% \mathrm{CI}=[-0.89,0.14]$, $\mathrm{OR}=0.69, t(280)=-1.87, P=0.24)$. This interaction was driven by gender differences in actual perceptions. Pairwise post-hoc tests indicated that male and female participants' GMPs were not significantly different across dislike $(b=0.29,95 \% \mathrm{CI}=[-0.25,0.82], \mathrm{OR}=1.33, t(280)=1.39$, $P=0.51)$, opposition $(b=0.19,95 \% \mathrm{CI}=[-0.34,0.73], \mathrm{OR}=1.21, t(280)=0.91, P=0.80)$, and social unacceptability $(b=0.52,95 \% \mathrm{CI}=[-0.02,1.07], \mathrm{OR}=1.69, t(280)=2.49, P=0.063)$; however, women's (relative to men's) actual perceptions of the behaviors were significantly more negative across disliking $(b=1.07,95 \% \mathrm{CI}=[0.56,1.58], \mathrm{OR}=2.91, t(280)=5.39, P<0.001)$, opposition $(b=0.93,95 \% \mathrm{CI}=[0.42,1.43], \mathrm{OR}=2.53, t(280)=4.75, P<0.001)$, and social unacceptability $(b=1.18,95 \% \mathrm{CI}=[0.66,1.69], \mathrm{OR}=3.24, t(280)=5.91, P<0.001)$.

Thus, while we found no credible evidence that men's group meta-perceptive judgments about how upset women would be were inaccurate, women's GMP judgments were inaccurate and overly negative, replicating the results from Experiment 1 in the domain of gender. It is important to note, however, that the men's 'accuracy' result was driven by differences in male and female participant's actual-perceptions. In other words, men's GMPs perceptions were closer to women's actual perceptions because women reported being more upset about the policy changes than men did. This pattern is likely the result of real-world power differences between the genders: men may be marginally less impacted and therefore less upset by disadvantageous policies in the contexts featured in our scenarios. More generally, Experiments 1 and 2 demonstrated GMP inaccuracy, but only as it pertained to the out-group in competitive or zerosum contexts. To examine whether GMPs reflect a negativity bias or a valence-independent 
extremity bias, Experiment 3 contrasted GMPs versus actual-perceptions in response to cooperative rather than competitive behaviors.

Experiment $3(\mathrm{~N}=499)$ utilized the same design as the GMP and actual-perception conditions from Experiment 1. While the scenarios pertained to the same political content, the nature of the behaviors was inverted such that the groups were taking cooperative actions, which either benefited the other group or disadvantaged the group taking the action. For example, instead of trying to make equal a partisan redistricting board controlled by the other party, in Experiment 3 the party taking action was trying to make equal a partisan redistricting board controlled by their own party. Participants in the GMP $(\mathrm{N}=233)$ and actual-perception $(\mathrm{N}=266)$ conditions were asked for their positive perceptions/GMPs (e.g., 1="Not Supportive", $100=$ "Extremely Supportive"), rather than negative perceptions. Otherwise the procedure was the same as Experiment 1, including the between-subjects random assignment to both condition and scenario.

In contrast to Experiments 1 and 2, Experiment 3 found no credible evidence for GMP inaccuracy in cooperative contexts across the support $(b=-0.02,95 \% \mathrm{CI}=[-0.25,0.21], \mathrm{OR}=0.98$, $\mathrm{z}=-0.20, P=0.84)$, liking $(b=0.12,95 \% \mathrm{CI}=[-0.11,0.35], \mathrm{OR}=1.13, \mathrm{z}=1.02, P=0.31)$, or political acceptability $(b=-0.05,95 \% \mathrm{CI}=[-0.28,0.18], \mathrm{OR}=0.95, \mathrm{z}=-0.42, P=0.67)$ measures. There was a main effect (but never an interaction) of party-accuracy for support $(b=0.44,95 \%$ $\mathrm{CI}=[0.20,0.67], \mathrm{OR}=1.55, \mathrm{z}=3.69, P<0.001)$, liking $(b=0.48,95 \% \mathrm{CI}=[0.25,0.71], \mathrm{OR}=1.61$, $\mathrm{z}=4.05, P<0.001)$, and political acceptability $(b=0.52,95 \% \mathrm{CI}=[0.29,0.75], \mathrm{OR}=1.69, \mathrm{z}=4.46, P$ $<0.001$ ), such that Democrats' positive reactions were slightly higher than Republicans' reactions. GMPs for both parties accurately tracked this mean-level difference. The findings from Experiment 3 parallel other work demonstrating that dyadic meta-perceptions are more 
accurate when two people are cooperative, but less so when competing ${ }^{25}$. Broadly, Experiment 3 also provides evidence that GMP inaccuracy represents specifically a negativity bias in competitive contexts, rather than an extremity bias in how we perceive the out-group will react to the in-group's actions in general.

Experiments 1, 2, and 3 are limited in several notable ways. First, they all utilize convenience samples (i.e., Mechanical Turk workers), and as such do not represent general population GMPs and actual-perceptions. Second, the previous experiments do not tell us whether people are inaccurate specifically about how the out-group sees the in-group's behavior or, more generally, how any group sees any other group's behavior. Experiment 4, a preregistered (see OSF: https://osf.io/atck5) extension of Experiment 1, utilized a nationallyrepresentative sample and included an in-group perception condition to addressed these limitations.

Experiment $4(\mathrm{~N}=536)$ featured the same scenarios from Experiment 1. Participants were randomly assigned, between-subjects, to the actual perception condition $(\mathrm{N}=170)$, GMP condition $(\mathrm{N}=206)$, both of which were the same as Experiment 1, or a new condition called the in-group perception condition $(\mathrm{N}=160)$. Participants in the in-group perception condition read the same scenarios as those in the actual perception condition, but instead of being asked for their individual perceptions they were asked how they believed "another [in-group member]" would perceive the scenarios. In contrast to Experiment 1, participants read and responded to all five scenarios (a repeated-measures factor, modeled as a random effect for participant).

Experiment 4 revealed significant differences between all three conditions on all three outcome measures (see Figure 2 for raw data distributions). Actual perceptions were lower than in-group perceptions for opposition $(b=-0.26,95 \% \mathrm{CI}=[-0.43,-0.09], \mathrm{OR}=0.77, \mathrm{z}=-2.93$, 
$P=0.003)$, unacceptability $(b=-0.25,95 \% \mathrm{CI}=[-0.43,-0.07], \mathrm{OR}=0.78, \mathrm{z}=-2.72, P=0.007)$, and disliking $(b=-0.34,95 \% \mathrm{CI}=[-0.52,-0.17], \mathrm{OR}=0.71, \mathrm{z}=-3.93, P<0.001)$. GMPs were higher than in-group perceptions for opposition $(b=0.51,95 \% \mathrm{CI}=[0.35,0.68], \mathrm{OR}=1.67, \mathrm{z}=6.10, P<$ $0.001)$, unacceptability $(b=0.43,95 \% \mathrm{CI}=[0.25,0.60], \mathrm{OR}=1.53, \mathrm{z}=4.87, P<0.001)$, and disliking $(b=0.41,95 \% \mathrm{CI}=[0.24,0.57], \mathrm{OR}=1.50, \mathrm{z}=4.83, P<0.001)$. The pairwise post-hoc contrasts between actual-perceptions and GMPs were also significant for opposition $(b=-0.77$, $95 \% \mathrm{CI}=[-0.97,-0.58], \mathrm{OR}=0.46, t(2669)=-9.27, P<0.001)$, unacceptability $(b=-0.67,95 \% \mathrm{CI}=[-$ $0.87,-0.47], \mathrm{OR}=0.51, t(2669)=-7.83, P<0.001)$, and disliking $(b=-0.75,95 \% \mathrm{CI}=[-0.95,-0.56]$, $\mathrm{OR}=0.47, t(2669)=-9.04, P<0.001)$, directly replicating the main finding of inaccurate GMPs from Experiment 1, but this time in a nationally representative sample. We also performed a direct replication of Experiment 4 using a convenience sample (again Mechanical Turk workers) and found practically identical results (see "Supplemental Experiment A").

Note that the differences between in-group perceptions and GMPs indicate that our inaccuracy findings for Experiments 1 and 2 cannot be explained entirely by the difference in referents across the actual perception judgments ("how would you feel") versus GMP ("how would an out-group member feel") judgments. In Experiment 4 the in-group judgment also uses a group-level referent ("how would an in-group member feel about the out-group's action") but is still significantly less negative than the GMP judgments.

Study $5(\mathrm{~N}=212)$ tested whether inaccurate GMPs are consequential by examining the relationship between GMPs and negative motive attributions towards the out-group. In this study, participants completed the GMP condition from Experiment 1. They then reported how much they agreed with the statement "[Out-group members] are purposefully obstructing the process surrounding the [specific scenario topic]" (1-100 slider scale, "Strongly Disagree" to 
"Strongly Agree"). Analyses indicated a significant positive linear association between belief that the out-group is obstructionist and negative GMPs of disliking $(b=2.12,95 \%$

$\mathrm{CI}=[1.40,2.84], \mathrm{OR}=8.34, \mathrm{z}=5.76, P<0.001)$, opposition $(b=1.95,95 \% \mathrm{CI}=[1.19,2.70]$, $\mathrm{OR}=7.00, \mathrm{z}=5.06, P<0.001)$, and political unacceptability $(b=1.66,95 \% \mathrm{CI}=[0.96,2.35]$, $\mathrm{OR}=5.24, \mathrm{z}=4.69, P<0.001)$. There was no significant main effect of party identification on disliking $(b=-0.04,95 \% \mathrm{CI}=[-0.37,0.30], \mathrm{OR}=0.96, \mathrm{z}=-0.22, P=0.83)$, opposition $(b=-0.11,95 \%$ $\mathrm{CI}=[-0.44,0.23], \mathrm{OR}=0.90, \mathrm{z}=-061, P=0.55)$, or political unacceptability $(b=-0.08,95 \% \mathrm{CI}=[-$ $0.42,0.26], \mathrm{OR}=0.92, \mathrm{z}=-0.47, P=0.64$ ). Thus, the more negative (and therefore inaccurate) participants' GMPs were, the more likely they were to believe the out-group is motivated by obstructionism. See Figure 3 for visualization of raw data and Pearson correlations.

Experiment $6(\mathrm{~N}=1122)$ sought to reduce the perception that the out-group is motivated

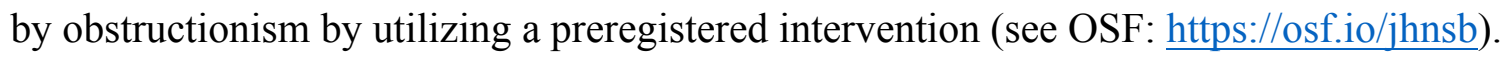
Building upon Study 5's design, after participants provided their three GMP ratings in response to one of the five political scenarios, participants were randomly assigned, between-subjects, to one of three conditions before reporting their perceived out-group obstructionism: the control ( $\mathrm{N}=396)$, "truth intervention" ( $\mathrm{N}=358)$, or "hypocrisy prevention intervention" condition $(\mathrm{N}=368)$. In the control condition participants were simply reminded of the GMP ratings they had provided on the previous page (i.e., no new information). In the truth intervention, participants were provided with the information from the control condition plus the true value for their out-group's actual perceptions (the mean of the representative sample responses from Experiment 4) for that same scenario. This allowed participants to see the (in)accuracy of their GMPs. Recall that in Experiment 4 we also found that participants inaccurately believed their ingroup would react less negatively than their out-group to the same behavior. Therefore, in the 
hypocrisy prevention intervention participants received all the information in the truth intervention while also receiving the exact true values for their in-group's actual perceptions (also drawn from Experiment 4), for the same scenario. As such, the hypocrisy intervention additionally prevented participants from anchoring on an inaccurate belief that the in-group's negativity would still be lower than the out-group's in the same scenario. This allowed us to test whether there was an added benefit to highlighting participants' (in)accuracy regarding the extent to which their in-group and out-group were similar in their actual perceptions.

As hypothesized, participants who were assigned to the truth intervention condition had significantly lower ratings of out-group obstructionism than did the control group $(b=-4.08,95 \%$ $\mathrm{CI}=[-7.67,-0.48], \beta=-0.155, t(1114)=-2.22, P=0.027)$. Those assigned to the hypocrisy prevention intervention also had significantly lower obstructionism ratings relative to control $(b=-4.64,95 \% \mathrm{CI}=[-8.22,-1.08], \beta=-0.177, t(1114)=-2.55, P=0.011)$. However, post-hoc pairwise comparisons indicated no statistically significant difference in obstructionism between the hypocrisy prevention and truth interventions $(b=-0.57,95 \% \mathrm{CI}=[-4.96,3.82], t(1115)=-0.304$, $P=0.95$ ), suggesting the hypocrisy prevention intervention provided no additional benefit above the truth intervention. There was also a main effect of party identification on obstructionism, with Democrats rating Republicans as higher on obstructionism that Republicans rated Democrats $(b=-3.84,95 \% \mathrm{CI}=[-6.88,-0.79], \beta=-0.146, t(1114)=-2.47, P=0.014)$; however, further analysis indicated no statistically significant party by condition interaction for either the truth intervention $(b=4.44,95 \% \mathrm{CI}[-2.97,11.88], t(1113)=1.17, P=0.24)$, or hypocrisy intervention $(b=0.83,95 \% \mathrm{CI}[-6.59,8.26], t(1112)=0.22, P=0.83)$. In other words, the interventions were not significantly more effective at reducing negative motive attributions among one party relative to the other. 
Further analysis revealed significant interactions of condition on GMP inaccuracy (operationalized as the mean difference between participants' GMPs and the true values, such that higher values $=$ more inaccurate and negative). We found that GMP inaccuracy moderated the effectiveness of the hypocrisy prevention intervention $(b=-0.17,95 \% \mathrm{CI}=[-0.33,-0.01], \beta=-$ $0.144, t(1112)=-2.09, P=0.037)$, and truth intervention $(b=-0.27,95 \% \mathrm{CI}=[-0.43,-0.12], \beta=-0.23$, $t(1113)=-3.39, P<0.001)$, relative to control. In other words, the interventions were more effective at reducing obstructionism for participants whose GMPs were relatively more inaccurate and negative. There was also a linear association between inaccuracy and perceived obstructionism $(b=0.44,95 \% \mathrm{CI}=[0.32,0.56], \beta=0.37, t(1114)=7.33, P<0.001)$, replicating the finding from Study 5. See Figure 4 for visualization of the effect of the interventions at one standard deviation above and below the mean of accuracy (see Supplementary Figure 4 for raw data distributions). As an exploratory measure, we followed up with participants a week after they completed Experiment 6 to see if the effect of the intervention persisted over time. We had a $73 \%$ response rate, but found no credible evidence for a continued effect of the intervention on a rating of general out-group obstructionism (see "Supplemental Experiment B").

The results of Experiment 6 provided support for the hypothesis that negative motivational attributions towards the out-group, such as obstructionism, were driven in part by inaccurate beliefs regarding how negatively the out-group perceived the collective behavior of one's in-group. They also suggest that simply providing individuals with concrete information regarding their inaccurate, and overly negative, GMPs can help reduce downstream negative attributions towards the out-group. However, we found no credible evidence that the hypocrisy prevention intervention provided additional benefit above the truth intervention, which suggests that participants were not anchoring on inaccurate beliefs about how the in-group would react to 
the same behavior. Given the central role motive attributions play in intergroup relations ${ }^{26,27}$, our findings highlight a potential avenue for future attempts at reducing intergroup hostility and conflict, and an avenue for further understanding the antecedents of negative and inaccurate motive attributions ${ }^{9,12}$.

\section{Discussion}

Across seven experiments and one survey we found that group meta-perceptions were consistently inaccurate and negatively biased across a variety of competitive intergroup contexts (i.e., gender, political parties), scenarios, and participant samples. Theoretically, our findings of negative and inaccurate GMPs across multiple intergroup domains - even in the absence of group labels as in the control condition of Experiment 1-parallel research on the interindividual-intergroup discontinuity effect (IIDE), which demonstrates that intergroup interactions are more hostile and competitive then interindividual interactions ${ }^{28,29}$. Importantly, the IIDE is observed both in actual behavior and in expectations of behavior, in that people expect future intergroup interactions to be more hostile than interpersonal interaction ${ }^{30}$. If people assume that intergroup interactions are going to be more hostile, this may partially explain why GMPs are overly negative and associated with negative motive attributions, although it does not explain why GMPs are so inaccurate. Similarly, while recent evidence suggests that perceptions of political party polarization in the US have become more negative and inaccurate over the past four decades ${ }^{18,31}$, this does not explain inaccurate GMPs in the domain of gender, why there is no evidence for GMP inaccuracy in cooperative political contexts, and why there is no evidence that inaccurate GMPs vary across the scenario content or party of the perceiver.

Several limitations in these experiments highlight fruitful avenues for future research. One assumption embedded in these studies is that actual perceptions represent ground truth. An 
alternative source of GMP inaccuracy may be actual perceivers downplaying their reactions to these events. For example, in Experiment 2, men might have been underreporting their dissatisfaction with losing resources, which would make women's GMPs look more inaccurate than they are. Furthermore, the use of random-probability sampling would be superior to the quota-matching methods we used in Experiment 4 for estimating the precise true population actual-perceptions of our stimuli. Second, we did not measure confidence in participants' own judgments, which should be related to GMP (in)accuracy as it is in other meta-perceptions research $^{32}$. Third, we found no statistically significant effect of our intervention on negative motive attributions a week after it was administered, though we hasten to note that we specifically designed our intervention to minimize the likelihood that our results were driven by demand effects. Furthermore, the attrition-rate of participants means our follow-up measurement a week later was likely underpowered. Future research should vary the strength and nature of any such interventions in order to understand better which qualities provide more (if any) benefit over time.

Conceptually, future research ought to examine the relationship between GMPs and other second-order judgments in intergroup contexts. Here we operationalized GMPs as judgments regarding out-group members' reactions to collective in-group behaviors, but GMPs can be measured along many features, including attitude ${ }^{33}$ and trait ${ }^{34}$ attributions (i.e., "how they see us"), dehumanization ${ }^{7}$ (i.e., "how human they think we are"), judgments of intent ${ }^{35}$, even group emotions $^{36}$. Understanding how GMPs across these judgments relate to, and are distinct from one another will be critical in building theory around the dynamics of and outcomes associated with GMPs in intergroup contexts. Lastly, future work should also seek to take advantage of current 
events as they are unfolding in order to see how inaccuracies in GMP are shaped during real world events related to issues with which people are very familiar.

Our findings highlight a consistent, pernicious inaccuracy in social perception, along with how these inaccurate perceptions relate to negative attributions towards out-groups. More broadly, inaccurate and overly negative GMPs exist across multiple competitive intergroup contexts, and we find no evidence they differ across the political spectrum. This suggests that there may be many domains of intergroup interaction where inaccurate GMPs could potentially diminish the likelihood of cooperation and instead exacerbate the possibility of conflict. However, our findings also highlight a straight-forward manner in which simply informing individuals of their inaccurate beliefs can reduce these negative attributions.

\section{Methods}

All studies were approved by Harvard University’s Institutional Review Board, and all participants gave their informed consent before participating. All participants, except those in Experiment 4, were collected on Amazon's Mechanical Turk platform (“Mturk”), and were located in the United States. Participants in Experiment 4 were collected through Qualtric Survey Panels, and the sample was quota-matched to US census data distributions of the following variables in the general population: age, gender, ethnicity, education, and income (see supplemental materials for demographic breakdown and quotas). All surveys were administered via the Qualtrics survey platform.

Participants. Samples from Experiments 1, 3, 4, 6 and Study 5 consist of self-identified Republicans and Democrats, and the sample of Experiment 2 consists of self-identified men and women. Experiment $1(\mathrm{~N}=408)$ and Experiment $2(\mathrm{~N}=286)$ had sample sizes of 170 per condition 
determined a priori with the goal of attaining 144 per condition (allowing for the detection of a small effect size, $f=0.15$ ) after excluding participants who failed comprehension checks (see Exclusions section below). Expecting to observe a reduced effect size in Experiment 3 ( $\mathrm{N}=499)$ relative to Experiment 1, we increased the a priori sample size to a target of 275 per condition, and collected 675 in the hopes of reaching 550 after exclusions. Experiment 4 had a preregistered sample size of $\mathrm{N}=500$, and Qualtrics purposefully oversampled to ensure a minimum of 500 quality responses (hence final $\mathrm{N}=536)$. For Study $5(\mathrm{~N}=212)$ we selected an a priori sample size of $\mathrm{N}=300$, with the goal of attaining approximately $\mathrm{N}=250$ after exclusions, the sample size at which small correlations stabilize ${ }^{37}$. Experiment $6(\mathrm{~N}=1122)$ had a preregistered sample size of $\mathrm{N}=1510$, in the hopes of obtained 1260 (enough to detect a small effect size) after exclusions.

Exclusions: In Experiment 1 we removed 12 responses due to three separate participants taking the study multiple times (all their responses were removed). A further 89 participants failed the comprehension check, and one participant was excluded for not completing the dependent variable ratings, leaving a final $\mathrm{N}=408\left(\mathrm{M}_{\mathrm{age}}=35.2,239\right.$ Women). In Experiment 2 we removed two responses due to one participant completing the study twice, another response due to a participant not providing their gender identity, and 56 participants who failed the comprehension check, leaving a final $\mathrm{N}=286\left(\mathrm{M}_{\text {age }}=36.2,156\right.$ Women $)$. In Experiment 3, 165 participants failed the comprehension check, and 12 responses were removed due to duplicate IP addresses, leaving a final $\mathrm{N}=499\left(\mathrm{M}_{\mathrm{age}}=35.1,293\right.$ Women $)$. In Experiment 4, 364 participants failed the comprehension check, and the Qualtrics manager continued collecting data until 536 participants (273 Women, Age Brackets: 165 in ages 18-34, 189 in ages 35-54, 182 in ages 55+), who met our demographic quotas, completed the study. In Study 5, 86 participants failed the comprehension check, and two participants were removed for not completing the dependent 
variable rating, leaving a final $\mathrm{N}=212\left(\mathrm{M}_{\mathrm{age}}=35.89,120\right.$ Women $)$. In Experiment 6, 349 participants failed the comprehension check, and 26 responses were removed due to duplicate Mturk ID or IP addresses, leaving a final $\mathrm{N}=1122\left(\mathrm{M}_{\mathrm{age}}=35.1,642\right.$ Women $)$. We did not weigh Mturk samples by political party or gender because we were interested in in-group versus outgroup dynamics, not the difference between, for example, Democrats and Republicans. In Experiment 4 we quota-matched to a 50/50 slip of Democrats and Republicans. Self-identified Independents were allowed to complete all studies (except Experiment 4), but were excluded from all analyses a priori.

Compensation: Experiments 1, 2, 3, and Study 5 paid \$0.10 and were advertised as taking one minute. Experiment 4 was advertised as taking 9 minutes (itself 4 minutes, but it was bundled with a separate 5-minute study which always came after Experiment 4), and participants were paid a preset amount of credit via Qualtrics Panel's internal payment system. Experiment 6 paid $\$ 0.15$ and was advertised as taking 60-90 seconds.

Procedure: We randomly assigned participants to condition and scenario (in Experiment 4 scenario order) across all the experiments and studies. Across scenarios, we also randomized the order of the dependent variable items (e.g. disliking, opposition). All randomization was facilitated through Qualtrics' randomization functions. The surveys were programmed to pipe the appropriate out-group and/or in-group labels into the scenarios and dependent variables ratings based on the participants' self-reported group affiliation. All dependent variables across all studies appeared as sliding scales with end-labels and tick-marks, but no visible numbers (except for the ratings in Experiment 6, in which a numeric value (1-100) appeared next to the slider 
when participants provided a response). Across all experiments and studies, except Experiment 4, excluded participants received full compensation.

Analyses: We analyzed Experiments 1-4 and Study 5 using mixed-effect beta-regressions (glmmTMB ${ }^{38}$ package, $\mathrm{v}$ 0.2.3) in $\mathrm{R}(\mathrm{v}$ 3.6.1) and Experiment 6 using linear mixed-effects modeling (lmerTest ${ }^{39} \mathrm{R}$ package, v 3.1-0). All post-hoc tests utilized the Tukey method for $P$ value adjustment and were conducted with the emmeans ${ }^{40} \mathrm{R}$ package (v. 1.4). We used betaregressions for Experiments 1-4 and Study 5 due to the highly skewed GMP response data, and transformed the data for the beta-regressions using established formulas ${ }^{41}$. As a robustness check we performed all non-preregistered beta-regression analyses (Experiments 1, 2, 3, and Study 5) using linear mixed effects modeling via the lmerTest R package: none of our results changed meaningfully. For Experiments 1, 3, 4, Study 5, and the main effects of Experiment 6, we report the results from models that include only the main effects because there were never any significant interactions among the fixed-effects; furthermore, the saturated models including fixed effects and the corresponding interactions did not improve model fit. Results for Experiment 2 are from the saturated models, and while we report the interaction of accuracy on condition in Experiment 6, we never find an interaction with party identification and do not report those saturated models. Across Experiments 1-4 we regressed the relevant dependent variable rating (dislike, opposition, political/social unacceptability) onto fixed effects for condition and the relevant group variable ("party accuracy" in Experiment 1, 3 and 4, "gender accuracy" in Experiment 2), a random effect with random intercepts for scenario (along with an random effect for participant in Experiment 4, due to the repeated measures), and in Experiment 2 an interaction term for the condition by group interaction. In Study 5 we regressed 
obstructionism onto each GMP item separately, including a fixed effect for party and a random effect with random intercepts for scenario. In Experiment 6 we regressed obstructionism onto condition including a fixed effect for party and a random effect with random intercepts for scenario, then replaced the fixed effect for party with the interaction of accuracy with condition. All tests were two-sided. Data analyses were not performed blind to the conditions of the experiments and studies. Figures were created using the R packages ggstatsplot ${ }^{42}$ (v. 0.0.12), $\operatorname{sjPlot}^{43}$ (v. 2.7.0), and $\operatorname{psych}^{44}$ (v. 1.8.12).

Experiments 4 and 6 were preregistered. Experiment 4 was preregistered on February $26^{\text {th }}, 2019$ and can be found here: https://osf.io/atck5. Experiment 6 was preregistered on March $19^{\text {th }}, 2019$ and can be found here: https://osf.io/jhnsb. No analyses deviate from the preregistrations.

\section{Data Availability}

All data that supported the findings of this study are publicly available in CSV format on the Open Science Framework: https://osf.io/zhysa/

\section{Code Availability}

All analyses reported in this study used the statistical software R (v 3.6.1). All R files are publicly available on the Open Science Framework: https://osf.io/zhysa/

\section{References}

1. Carlson, E. N. Meta-accuracy and relationship quality: Weighing the costs and benefits of knowing what people really think about you. Journal of Personality and Social Psychology 111, 250-264 (2016). 
2. Carlson, E. N., Vazire, S. \& Furr, R. M. Meta-insight: Do people really know how others see them? Journal of Personality and Social Psychology 101, 831-46 (2011).

3. Vazire, S. \& Carlson, E. N. Others sometimes know us better than we know ourselves. Current Directions in Psychological Science 20, 104-108 (2011).

4. Vorauer, J. D., Main, K. J. \& O’Connell, G. B. How do individuals expect to be viewed by members of lower status groups? Content and implications of meta-stereotypes. Journal of Personality \& Social Psychology 75, 21 (1998).

5. Vorauer, J. D., Hunter, a J., Main, K. J. \& Roy, S. a. Meta-stereotype activation: Evidence from indirect measures for specific evaluative concerns experienced by members of dominant groups in intergroup interaction. Journal of Personality and Social Psychology 78, 690-707 (2000).

6. Frey, F. E. \& Tropp, L. R. Being seen as individuals versus as group members: Extending research on metaperception to intergroup contexts. Personality and Social Psychology Review 10, 265-280 (2006).

7. Kteily, N., Hodson, G. \& Bruneau, E. They see us as less than human: Metadehumanization predicts intergroup conflict via reciprocal dehumanization. Journal of Personality and Social Psychology 110, 343-370 (2016).

8. Sigelman, L. \& Tuch, S. A. Metastereotypes: Blacks' perceptions of whites' stereotypes of blacks. Public Opinion Quarterly 61, 87 (1997).

9. Finchilescu, G. Intergroup anxiety in interracial interaction: The role of prejudice and metastereotypes. Journal of Social Issues 66, 334-351 (2010). 
10. Klein, O. \& Azzi, A. E. The strategic confirmation of meta-stereotypes: How group members attempt to tailor an out-group's representation of themselves. British Journal of Social Psychology 40, 279-293 (2001).

11. Waytz, A., Young, L. L. \& Ginges, J. Motive attribution asymmetry for love vs. hate drives intractable conflict. Proceedings of the National Academy of Sciences 111, 15687-15692 (2014).

12. Lau, T., Morewedge, C. K. \& Cikara, M. Overcorrection for social-categorization information moderates impact bias in affective forecasting. Psychological science 27, 13401351 (2016).

13. Goldstein, N. J., Vezich, I. S. \& Shapiro, J. R. Perceived perspective taking: When others walk in our shoes. Journal of Personality and Social Psychology 106, 941-960 (2014).

14. Saguy, T. \& Kteily, N. Inside the opponent's head: Perceived losses in group position predict accuracy in metaperceptions between groups. Psychological Science 22, 951-958 (2011).

15. Robinson, R. J., Keltner, D., Ward, A. \& Ross, L. Actual versus assumed differences in construal: 'Naive realism' in intergroup perception and conflict. Journal of Personality and Social Psychology 68, 404-417 (1995).

16. Chambers, J. R. \& Melnyk, D. Why do I hate thee? Conflict misperceptions and intergroup mistrust. Personality and Social Psychology Bulletin 32, 1295-1311 (2006).

17. Chambers, J. R., Baron, R. S. \& Inman, M. L. Misperceptions in intergroup conflict. Psychological Science 17, 38-45 (2006).

18. Westfall, J., Van Boven, L., Chambers, J. R. \& Judd, C. M. Perceiving political polarization in the United States: Party identity strength and attitude extremity exacerbate the perceived partisan divide. Perspectives on Psychological Science 10, 145-158 (2015). 
19. Bush, G. W. President Bush's address to a joint session of Congress and the nation. (2001).

20. Sunstein, C. R. Why they hate us: The role of social dynamics. Harvard Journal of Law \& Public Policy 429-440 (2002).

21. Zakaria, F. The politics of rage: Why do they hate us? Newsweek (2001).

22. Merskin, D. The construction of arabs as enemies: Post-September 11 discourse of George W. Bush. Mass Communication and Society 7, 157-175 (2004).

23. Rogers, T. \& Feller, A. Reducing student absences at scale by targeting parents' misbeliefs. Nature Human Behaviour 2, 335-342 (2018).

24. Nyhan, B. \& Reifler, J. The roles of information deficits and identity threat in the prevalence of misperceptions. Journal of Elections, Public Opinion and Parties 1-23 (2018).

25. Eisenkraft, N., Elfenbein, H. A. \& Kopelman, S. We know who likes us, but not who competes against us : Dyadic meta-accuracy among work colleagues. Psychological Science (2017).

26. Reeder, G. D., Vonk, R., Ronk, M. J., Ham, J. \& Lawrence, M. Dispositional attribution: Multiple inferences about motive-related traits. Journal of Personality and Social Psychology 86, 530-544 (2004).

27. Miller, D. T. \& Nelson, L. D. Seeing approach motivation in the avoidance behavior of others: Implications for an understanding of pluralistic ignorance. Journal of Personality and Social Psychology 83, 1066-1075 (2002).

28. Insko, C. A., Schopler, J., Hoyle, R. H., Dardis, G. J. \& Graetz, K. A. Individual-group discontinuity as a function of fear and greed. Journal of Personality and Social Psychology 58, 68-79 (1990). 
29. Wildschut, T., Pinter, B., Vevea, J. L., Insko, C. A. \& Schopler, J. Beyond the group mind: A quantitative review of the interindividual-intergroup discontinuity effect. Psychological Bulletin 129, 698-722 (2003).

30. Pemberton, M. B., Insko, C. A. \& Schopler, J. Memory for and experience of differential competitive behavior of individuals and groups. Journal of Personality \& Social Psychology 71, 14 (1996).

31. Enders, A. M. \& Armaly, M. T. The differential effects of actual and perceived polarization. Political Behavior (2018).

32. Carlson, E. N., Furr, R. M. \& Vazire, S. Do we know the first impressions we make? Evidence for idiographic meta-accuracy and calibration of first impressions. Social Psychological and Personality Science 1, 94-98 (2010).

33. Stern, C. \& Kleiman, T. Know thy outgroup: Promoting accurate judgments of political attitude differences through a conflict mindset. Social Psychological and Personality Science 6, 950-958 (2015).

34. Stroessner, S. J. \& Dweck, C. S. Inferring group traits and group goals. in Social Perception: From Individuals to Groups (eds. Stroessner, S. J. \& Sherman, J. W.) 177-196 (Psychology Press, 2015).

35. Ames, D. \& Fiske, S. Perceived intent motivates people to magnify observed harms. Proceedings of the National Academy of Sciences 112, 3599-605 (2015).

36. Goldenberg, A., Saguy, T. \& Halperin, E. How group-based emotions are shaped by collective emotions: Evidence for emotional transfer and emotional burden. Journal of Personality and Social Psychology 107, 581-596 (2014). 
37. Schönbrodt, F. D. \& Perugini, M. At what sample size do correlations stabilize? Journal of Research in Personality 47, 609-612 (2013).

38. Magnusson, A. et al. glmmTMB: generalized linear mixed models using template model builder. Version 0.2.3. (2019). Available at: https://CRAN.Rproject.org/package=glmmTMB .

39. Kuznetsova, A., Brockhoff, P. B. \& Christensen, R. H. B. lmerTest: tests in linear mixed effects models. Version 3.1-0. (2019). Available at: https://CRAN.Rproject.org/package=lmerTest.

40. Lenth, R., Singmann, H., Love, J., Buerkner, P. \& Herve, M. emmeans: estimated marginal means, aka least-squares means. Version 1.4. (2019). Available at: https://CRAN.Rproject.org/package $=$ emmeans.

41. Smithson, M. \& Verkuilen, J. A better lemon squeezer? Maximum-likelihood regression with beta-distributed dependent variables. Psychological Methods 11, 54-71 (2006).

42. Patil, I. \& Powell, C. ggstatsplot: "ggplot2" based plots with statistical details. Version 0.0.12. (2019). Available at: https://CRAN.R-project.org/package=ggstatsplot.

43. Lüdecke, D., Bartel, A., Schwemmer, C. \& Powell, C. sjPlot: data visualization for statistics in social science. Version 2.7.0. (2019). Available at: https://CRAN.Rproject.org/package $=$ sjPlot.

44. Revelle, W. psych: procedures for psychological, psychometric, and personality research. Version 1.8.12. (2019). Available at: https://CRAN.R-project.org/package=psych.

\section{Acknowledgments}

Work on this project by MC was supported by a National Science Foundation Award (BCS1551559). The funders had no role in study design, data collection and analysis, decision to 
publish or preparation of the manuscript. JL received no specific funding for this work. We thank members of the Harvard Intergroup Neuroscience Lab, Sidanius Lab, and attendees to the 2018 East Coast Doctoral Conference for their helpful comments, Z. Ingbretsen and N. Hunt for help with data collection, and I. Zahn and S. Worthington for statistical assistance.

\section{Author Contributions}

J.L. and M.C. designed all experiments and wrote the manuscript. J.L. completed data collection and analysis under the supervision of M.C.

\section{Competing Interests}

The authors declare no competing interests

\section{Figure Legends}

Figure 1: Raw data from Experiment 1 by condition and dependent variable. $\mathrm{N}=408$ (collected via Mechanical Turk). By Condition: Actual Perceptions N=143, Anonymized/Control GMPs N=136, Political Party GMPs=129. In the two GMP conditions participants reported how much they thought their out-group, or an anonymized political party (control), would dislike, oppose, and find unacceptable the ingroup's/other party's action in the scenario. Red dots and corresponding numbers are sample means, the boxplot center lines are sample medians. Participants in the political party GMP condition significantly overestimated the negative perceptions of out-group participants in the actual-perception condition on action dislike $(b=1.51,95 \% \mathrm{CI}=[1.19,1.83], \mathrm{OR}=4.53, \mathrm{z}=9.27, P<0.001)$, opposition to the action $(b=1.40,95 \% \mathrm{CI}=[1.09,1.72], \mathrm{OR}=4.08, \mathrm{z}=8.78, P<0.001)$, and political unacceptability of the action $(b=1.36,95 \% \mathrm{CI}=[1.04,1.67], \mathrm{OR}=3.89, \mathrm{z}=8.46, P<0.001)$. Participants in the control meta-perception condition significantly overestimated the negative perceptions of those in the actual-perception condition on dislike $(b=1.32,95 \% \mathrm{CI}=[1.02,1.62], \mathrm{OR}=3.74, \mathrm{z}=8.55, P<0.001)$, opposition $(b=1.22,95 \%$ $\mathrm{CI}=[0.93,1.52], \mathrm{OR}=3.40, \mathrm{z}=8.15, P<0.001)$, and political unacceptability $(b=1.13,95 \% \mathrm{CI}=[0.83,1.42]$, $\mathrm{OR}=3.08, \mathrm{z}=7.45, P<0.001$ ). Pairwise post-hoc tests indicate no statistically significant difference between responses in the control meta-perceptions vs. GMP conditions on dislike $(b=-0.19,95 \% \mathrm{CI}=[-$ $0.54,0.15], \mathrm{OR}=0.83 t(402)=-1.30, P=0.40)$, opposition $(b=-0.18,95 \% \mathrm{CI}=[-0.52,0.16], \mathrm{OR}=0.83$, $t(402)=-1.24, P=0.43)$, and political unacceptability $(b=-0.23,95 \% \mathrm{CI}=[-0.58,0.11], \mathrm{OR}=0.79, t(401)=-$ $1.58, P=0.26)$. These results provide evidence of overly pessimistic GMPs.

Figure 2: Raw data from Experiment 4 by condition and dependent variable. Sample sizes listed in figures are the number of judgments (across five repeated measures). Total $\mathrm{N}=538$ (nationally representative sample collected via Qualtrics survey panels). By Condition: Actual Perceptions N=170, Ingroup Perception $\mathrm{N}=160$, GMPs $=206$. Red dots and corresponding numbers are sample means, the boxplot center lines are sample medians. Actual perceptions were lower than in-group perceptions for opposition $(b=-0.26,95 \% \mathrm{CI}=[-0.43,-0.09], \mathrm{OR}=0.77, \mathrm{z}=-2.93, P=0.003)$, unacceptability $(b=-0.25,95 \%$ $\mathrm{CI}=[-0.43,-0.07], \mathrm{OR}=0.78, \mathrm{z}=-2.72, P=0.007)$, and disliking $(b=-0.34,95 \% \mathrm{CI}=[-0.52,-0.17], \mathrm{OR}=0.71$, $\mathrm{z}=-3.93, P<0.001)$. GMPs were higher than in-group perceptions for opposition $(b=0.51,95 \%$ $\mathrm{CI}=[0.35,0.68], \mathrm{OR}=1.67, \mathrm{z}=6.10, P<0.001)$, unacceptability $(b=0.43,95 \% \mathrm{CI}=[0.25,0.60], \mathrm{OR}=1.53$, $\mathrm{z}=4.87, P<0.001)$, and disliking $(b=0.41,95 \% \mathrm{CI}=[0.24,0.57], \mathrm{OR}=1.50, \mathrm{z}=4.83, P<0.001)$. The pairwise post-hoc contrasts between actual-perceptions and GMPs were also significant for opposition 
$(b=-0.77,95 \% \mathrm{CI}=[-0.97,-0.58], \mathrm{OR}=0.46, t(2669)=-9.27, P<0.001)$, unacceptability $(b=-0.67,95 \%$ $\mathrm{CI}=[-0.87,-0.47], \mathrm{OR}=0.51, t(2669)=-7.83, P<0.001)$, and disliking $(b=-0.75,95 \% \mathrm{CI}=[-0.95,-0.56]$, $\mathrm{OR}=0.47, t(2669)=-9.04, P<0.001)$. These results provide evidence of overly pessimistic GMPs and overly pessimistic judgments of the in-group's reactions.

Figure 3: Distributions, Pearson correlations, and scatterplots for the three GMP ratings and beliefs about out-group obstructionism in Study 5. $\mathrm{N}=212$ (collected via Mechanical Turk). Scatterplot lines are linear regression lines, shaded area around lines are $95 \%$ confidence intervals. Correlations: Disliking - Opposition $(r=0.83,95 \% \mathrm{CI}=[0.79,0.87], t(208)=21.73, \mathrm{P}<0.001)$, Disliking - Unacceptable $(r=0.73,95 \% \mathrm{CI}=[0.66,0.79], t(210)=15.50, \mathrm{P}<0.001)$, Disliking - Obstructionism $(r=0.33,95 \%$ $\mathrm{CI}=[0.20,0.45], t(210)=5.08, \mathrm{P}<0.001)$, Unacceptable - Opposition $(r=0.74,95 \% \mathrm{CI}=[0.68,0.80]$, $t(208)=16.02, \mathrm{P}<0.001)$, Unacceptable - Obstructionism $(r=0.29,95 \% \mathrm{CI}=[0.16,0.40], t(210)=4.32, \mathrm{P}<$ $0.001)$, and Obstructionism - Opposition $(r=0.32,95 \% \mathrm{CI}=[0.19,0.43], t(208)=4.80, \mathrm{P}<0.001)$. These data indicate a positive linear association between pessimistic GMPs and the belief that the out-group is purposefully obstructionist.

Figure 4: Effect of condition on obstructionism, by accuracy, in Experiment 6. $\mathrm{N}=1122$ (collected via Mechanical Turk). By Condition: Control=396, Hypocrisy Intervention=368, Truth Intervention=358. GMP inaccuracy moderated the effectiveness of the hypocrisy prevention intervention $(b=-0.17,95 \%$ $\mathrm{CI}=[-0.33,-0.01], \beta=-0.144, t(1112)=-2.09, P=0.037)$, and truth intervention $(b=-0.27,95 \% \mathrm{CI}=[-0.43$,$0.12], \beta=-0.23, t(1113)=-3.39, P<0.001)$ at reducing obstructionism. In other words, the interventions were more effective at reducing obstructionism for participants whose GMPs were relatively more inaccurate and negative. Here inaccuracy is plotted at one standard deviation above and below the mean inaccuracy $(\mathrm{M}=22, \mathrm{SD}=22)$. $-1 \mathrm{SD}$ equals an inaccuracy of zero, meaning that the participant was on average perfectly accurate in their GMPs. +1 SD equals an inaccuracy of 44 , meaning that the participant on average overestimated out-group negativity by 44 points (on a 100-point scale). Bars are $95 \%$ confidence intervals. 